\title{
STIMULATION SURFACES IN URBAN PLACES
}

\author{
Martina MAJOROŠOVÁ ${ }^{1 *}$, Eva MAZANCOVÁ ${ }^{2}$
}

\section{Abstract}

The aim of this article is to point out the potential of urban spaces that have not been primarily meant to be barefoot parks. The stimulation of bare feet is used as a part of therapy or for the prevention of plantar problems. The high number of research papers or blogs available about bare feet shows the interest in this topic among scientists, doctors and the broader population. People are usually shod in a city environment. An analysis of some existing barefoot/sensomotoric spaces compares 3 different projects located in Italy, Germany, and Colombia. The paper shows the common and different approaches in information systems and the amount, variability, and spatial arrangement of stimulation surfaces of these projects. The same method of categorization is used in the analysis of a newly reconstructed park in Slovakia, which was built without a request for a barefoot space. A comparison of these analyses shows the high potential for a regular park having a barefoot area. This research proves that barefoot places in urban areas could be instituted without any significant financial or construction interventions.

\section{Address}

1 Dept. of Land and Water Resources Management, Slovak University of Technology in Bratislava, Faculty of Civil Engineering, Slovakia

2 barefu s.r.o., Severná 18, 97401 Banská Bystrica, Slovakia

* Corresponding author: martina.majorosova@stuba.sk

\section{Key words}

- Stimulation surfaces,

- Barefoot spaces,

- Urban spaces,

- Barefoot areas/parks,

- Barefoot walking.

\section{INTRODUCTION}

Vegetation provides many hygienic, climatic, ecological and economic functions. The healing function of vegetation has been underestimated on many occasions. Healing landscape designs were known in the ancient Chinese, Greek, and Roman cultures (Belčáková et al., 2018). The earliest known list of healing plants, which is from China, is around 5000 years old. Moreover, healing herbs surrounded medieval monasteries because people knew that vegetation could be a source of healing miracles. In recent years, interest in a healthy environment is arising again. Healing landscape designs need to be developed both on public as well as private land. One of the new strategies in urban landscapes is barefoot landscape design. The design needs to be developed based on natural play, sensory, therapeutic, and healing principles for all ages, stages, and abilities (Souter-Brown, 2018).

Leonardo da Vinci understood the perfection of human feet, which he expressed in one of his famous quotes: "The human foot is a masterpiece of engineering and a work of art."
To develop such a unique foot and master a specialized gait took humans four million years (Lieberman, 2013). The control of balance and movements is the result of the complete cooperation of 26 bones, 33 joints, more than a hundred muscles, tendons and ligaments, and thousands of nerve endings in the sole and the toes (Tolja \& Don, 2019).

A study in the United States showed an alarming increase in foot problems during adolescence. While at birth just $1 \%$ of the participants had a foot problem, by age five, it was already $41 \%$, and by age 20 , it was the incredible number of $80 \%$ (Rossi, 1999). Observations of habitual barefoot walkers show that they anatomically have wider feet (D'aout et al., 2009), a reduced step/stride length (Lythgo et al., 2009; Oeffinger et al., 1999; Wolf et al. 2008), flatter foot placement (D'aout et al., 2009), and many more benefits. A systematic review of this topic has been analysed in 466 articles (Franklin, 2015). One of the conclusions is that footwear mainly affects the kinematics and kinetics of the gait acutely and chronically. This means that people who are shod most of the time during their lives have a different style of gait as well as shape of their feet than those who are habitual- 
ly barefoot. For example, habitually barefoot walkers exhibit lower peak plantar pressure and pressure impulses, whereas peak plantar pressure is increased in the habitually shod wearer, who walks barefoot. Suggestions have been made that the habitually unshod foot is less prone to injuries than the shod one (Robbins et al., 1987; Robbins et al., 1988), and it has indeed been found that people from various regions who have never worn shoes have relatively few foot disorders (Africans (Engle \& Morton, 1931); Chinese (Schulman, 1949); and Solomon Island inhabitants (James, 1939)). In his study, D'Aout (2009) suggests that frequent barefoot walking, especially for children, can help to preserve natural foot function. Also, walking barefoot on stimulative surfaces is a technique accepted worldwide among physiotherapists and podiatrists for the prevention and correction of plantar problems.

The first evidence of shoes is from approximately 40,000 years ago (Trinkaus \& Shang, 2008). Over time the idea of protecting feet by open-toe sandals or flexible leathers has evolved into the idea of aesthetic and fashionable products. Regular shoes are often narrow or padded and do not respect the actual shape of the human feet. This leads to the deformation of feet, including hammertoes and upturned toes, hallux valgus, sunken forefeet, toes growing closer together, bunions, corns, and many more problems (Rossi, 1999). Despite evidence of negative effects from wearing shoes, Western society expects people to be shod. There has therefore been an increase in the production of minimalist shoes in recent years. The main idea of these shoes is to free the feet and give them the possibility of working as if they were bare. Simultaneously, minimalist shoes offer a protective surface against the likelihood of cuts, abrasions, and infections from mechanical insults (Squadrone \& Gallozzi, 2009; Menant et al. 2008).

Nevertheless, proper research comparing the effects of minimalist shoes and actual bare feet on kinetics and balance is needed. Although walking outdoors in minimalist shoes allows legs to move as if they were barefoot, the movements of a user who usually wear ordinary shoes are not the same as having no foot protection at all.

In a shod population, acute and long-term exposure to walking barefoot in exterior changes the way of walking. On the other hand, wearing minimalist shoes only makes small changes compared to the walking usual style in shoes. Since the shod population prefers to walk through the heel, keeping this style of gait while wearing minimalist shoes could cause more problems than benefits. The difference between actual walking barefoot and wearing minimalist shoes seems to be in the lack of information the nerve endings get. Even a fragile layer of sole protection diminishes a high amount of stimulation. Walking properly in minimalist shoes would be the answer to the need of society to protect the feet and to be fashionable and for feet to work in the way they were made by evolution to do. However, the transition to relearning how to stand, walk, run, or just use the feet needs stimulation locations that invite people to take off their shoes.

Today, the lifestyles of many people include wearing some shoes for the whole day. The interior of the home is therefore the last place for a "barefoot paradise." However, most floor surfaces are flat and boring; there are already projects focusing on home stimulation (Mazancova \& Kotradyova, 2017). Environments such as parks, forests, beaches, gardens, lawns or fields are more welcoming to bare feet than concrete areas. The stimulation in these locations is based on the high concentration of different stimuli, i.e., changes in density, hardness, the temperature, and other aspects of the ground. This is also the principle of barefoot path walks that are popular in many countries. To build and maintain this kind of path usually requires additional construction and financial inputs into the existing environment.

Not only natural but also urban exterior surfaces offer a wide range of different stimulations. However, practicing barefoot walking in cities is almost never done. The most important reasons why people do not walk barefoot are fear of injury, fear of excrement, glass, and dirt, cold weather, and social conventions (questionnaire Mazancová, 2016). People has freedom in choosing directions that are not legally regulated and they can change their direction without any expectations, without thinking, and they can be suddenly injured. The motive can be the appearance of a familiar, interesting sight, an unexpected sound etc. (Kapski et al., 2020). By taking action to eliminate or reduce these aspects that stop people from taking their shoes off and by creating areas that invite visitors to go barefoot in an urban environment, the involvement and use of bare feet in everyday life would be increased. Such exposure of the legs and feet to stimulatory surfaces could lead to their further activation by strengthening and gradually transforming ordinary walking so that it is more similar to that of naturally barefoot individuals. A more detailed analysis of sensory areas and surfaces could furnish valuable information, including the parameters needed in the design of stimulative spaces.

This paper analyses three large barefoot areas in Italy, Germany, and Colombia. A comparison of their features, including a set of the parameters that determine the potential of stimulative surfaces in existing urban spaces, could help define the main approaches to creating such spaces. Individual parameters are also applied to a park in Slovakia that was not meant to be a barefoot park. The theoretical study of this park offers an example of how to recognise the potential of such space and what approach to choose; it also compares the pros and cons of two different examples of information system designs. Each design is also analysed from a technical point of view. The aim of this article is to show the opportunities offered by existing urban areas, how to recognize them, and which approach to choose when creating a stimulative space.

\section{MATERIALS AND METHODS}

\subsection{Selection of the reference barefoot areas}

In this study, we focused on barefoot areas located in urbanized areas. Three existing barefoot areas were selected, i.e., Parco de los pies descanzos in Colombia, Barefuss Park in Germany and Percorso di barefooting in Italy. Afterwards, we selected a new park in Slovakia that has the potential to be a barefoot area.

Parco de los pies descanzos is located in Medellin, Colombia. The area, which has a fountain, measures approximately $45 \mathrm{~m}^{2}$. It has five different surfaces with a total of seven transitions from one material to another. Its visitors are mainly locals, who use this place to relax. The information system provided motivates people to take off their shoes but has only a few pieces of information about walking barefoot.

Barefuss Park in Germany, which is located in the Kurpark Bad Wörishofen, is a part of a spa / thermal resort park. It is a trail around $2 \mathrm{~km}$ long with twenty-three different stops and forty transitions. The visitors are mainly guests of the thermal resort. The information system provided is a complex of tables belonging to every stand. It explains the philosophy of barefoot execise, motivates people to take off their shoes, and gives information and an interesting story about every surface.

Percorso di barefooting, which is located in the town of the Morgex in Valle de Aosta, is connected with a sensory educational walking path in a forest. It is an approximately $800 \mathrm{~m}$ long path with twenty-one surfaces and thirty-one transitions. The visitors are mainly season tourists, but during the year, there are also local visitors. The information system contains two tables about different surfaces and the barefooting ideology at the beginning of the path. Informative tables on the trail belong to the educational path or encourage caution on some surfaces. These tables are also adapted for blind people.

Landererov Park, which is being used as a demonstration of a newly-built park appropriate for establishing barefoot functions, is located in Bratislava, Slovakia. The park measures approximately 

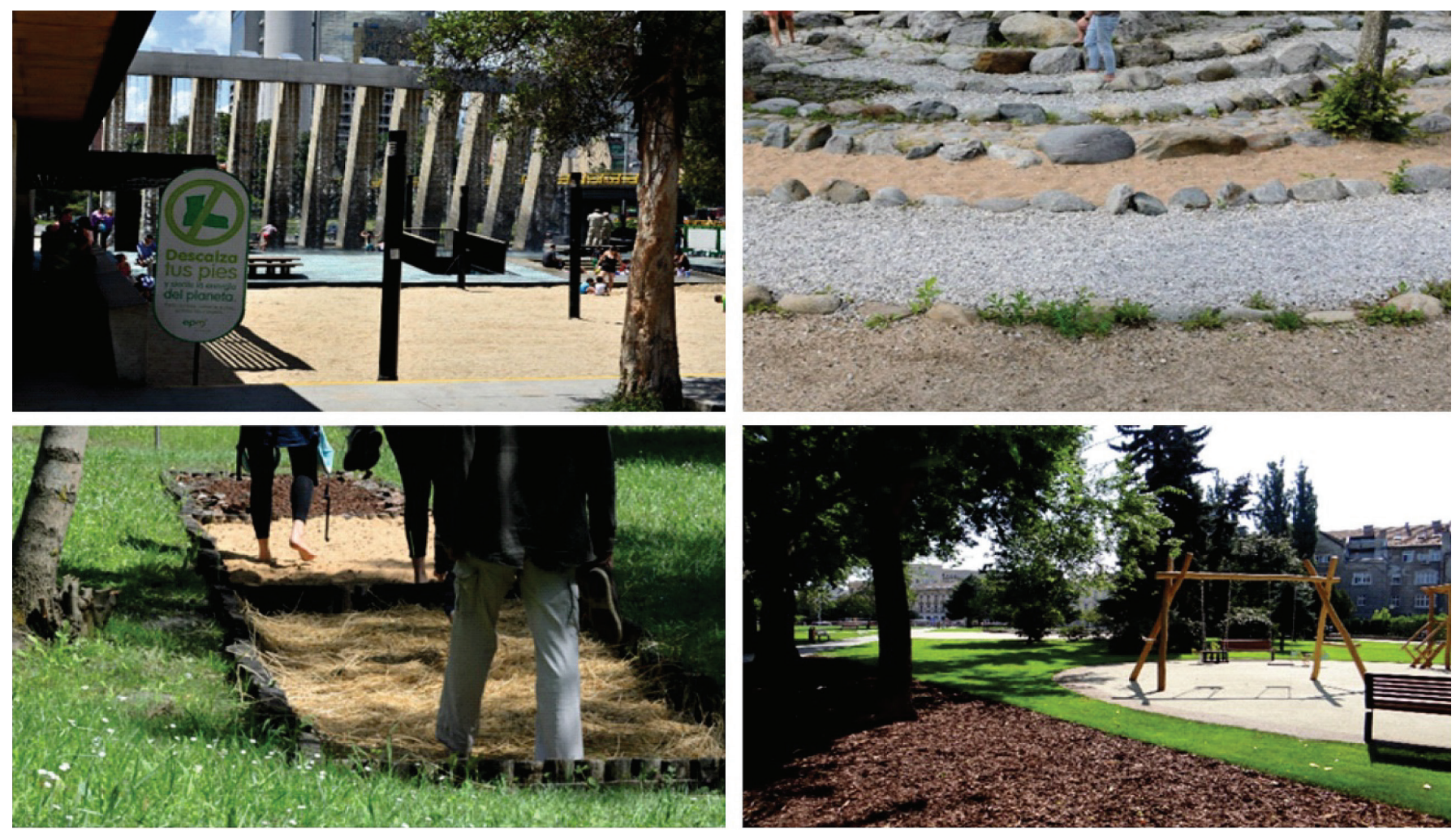

Fig. 1 Top left - Parco de los pies descanzos, Medellin, Colombia; Top right - Barefuss Park, Kurpark Bad Wörishofen, Germany; Bottom left - Percorso di barefooting, Morgex, Italy, Bottom right - The Landererov Park in Slovakia (Photo source: J. Mazanec 2013-2018, M. Majorošová, 2018).

$8000 \mathrm{~m}^{2}$ and consists of 6 surfaces. As the park is located in the center of Bratislava, its visitors include tourists and people living in the area.

All the parks (see Figure 1) selected for this study have been personally visited by at least one of the paper's authors. The sizes of all the spaces selected are varied. The barefooting function of the three existing barefoot spaces was clearly given and the purpose was fully executed.

\subsection{Parameters measured}

The parameters evaluated in the three parks selected were: the number of different materials, natural versus artificial materials, rigid versus loose materials, the transitions between the materials, the areas of the stands selected, the fencing of the area, the usual type of visitors, the colours of the materials (impact on the temperature), and the information system (the form of information provided about the barefoot area).

\subsection{Measurements}

The measurements and all the comparisons of the barefoot areas selected were made personally. All the areas were physically visited, and all the photos were taken by the authors of the article.

\subsection{Application of the findings on the potential area}

We selected an existing but new park that has the potential to be a barefoot area. Based on our previous findings, we will show different approaches to changing the existing park to a barefoot area.

\section{RESULTS}

\subsection{General results from the comparison of the measured parameters in the 3 existing barefoot spaces}

By comparing existing barefoot parks that are successful, we obtained a more specific overview of the important parameters of these kinds of projects. All the comparisons of the parameters are listed in Table 1. The placement of a barefoot park can vary from an urban environment to a rural area. Because of the natural connection between relaxation and being barefoot, sensomotoric paths are great additions to parks, fountains (water areas) or spa/health resorts parks. The different types of materials do not need to be numerous. What is important is the variety of rigid and loose materials and the transitions between the different surfaces. The areas of the stands selected can be connected on one trail, separated into stages on a trail and connected by a different material (grass, gravel, ground, etc.), or can be a solid area divided into different surfaces with a free direction of movement. The natural diversity of the colours of the materials has an impact on the temperature of the surfaces. The temperature of a material needs to be taken into consideration in a warmer climate. Because barefoot parks invite people to take off their shoes, they raise the issue of safety. A protected and clean environment can be secured by fencing the area or having a responsible employee for the place. People are usually held personally responsible for their use of a barefoot area. A barefoot park can enrich the quality of the daily life of its local visitors, but it can also be an interesting touristic area. One advantage of barefoot walking is that people of a wide range of ages can practice it. Based on this fact, it is a great activity for mixing people from different generations. 
One of the most important elements is the information system, which should invite and motivate people to take off their shoes. The presentation of an area as a barefoot site brings up questions about the necessity of shoes and opens up the possibility of being unshod. Proper information tables should provide information about barefoot walking but also about careful transitions from shoes to bare feet.

\subsection{Specific results}

The research shows three different approaches to stimulative spaces:

- stimulative stands

- stimulative pathways

- a stimulative area

Stimulative stands: this approach is used at the Barefuss Park, Kurpark Bad Wörishofen project. The stimulative route includes stands with natural or added surfaces that are marked with an information board. The individual stands are connected by grassy areas or gravel paths. Thanks to this approach, it is possible to create a stimulative path with fewer materials added. Its maintenance must ensure that care is taken not only on the stimulation stands but also on the transition areas. This approach is also useful in places with variable surfaces and walkable transition materials. This approach naturally motivates the visitor to walk barefoot not only on stimulating surfaces but also outside.

Stimulative pathway: this approach is used at Percorso di barefooting, Morgex, Valle de Aosta, Italy. The added materials are placed in insulated stations that are connected. This approach offers a large concentration of materials and possible transitions. In the information system, one information board at the beginning is sufficient, as the route along the stimulating surfaces continuously passes from one surface to another. The visitor is motivated to stimulate his feet on the designated surfaces. As part of the maintenance, it is necessary to provide appropriate service on the stimulation materials or transition areas if they are part of the route.

Stimulative area: this approach is used at Parco de los descanzos (part with a fountain), Medellin, Colombia. The stimulative area is a safe space for walking barefoot. Within this area, various materials are used that are directly connected to the materials in its surroundings. The entire area requires maintenance and care. It is advisable to connect such a space to a rest area or a playground. One information board is sufficient for the entire area. In the case of a larger area, one primary barefoot information board and a small supplementary board inviting people to be shod are sufficient.

Tab. 1 Measured parameters (E. Mazancová, 2020).

\begin{tabular}{|c|c|c|c|}
\hline Place & $\begin{array}{l}\text { Parco de los pies descanzos } \\
\text { (part with fountain), Medellin, } \\
\text { Colombia }\end{array}$ & $\begin{array}{l}\text { Barefuss park, Kurpark Bad } \\
\text { Wörishofen, Germany }\end{array}$ & $\begin{array}{l}\text { Percorso di barefooting, Morgex, } \\
\text { Valle de Aosta, Italy }\end{array}$ \\
\hline Environment & $\begin{array}{l}\text { part of the city centre of } \\
\text { Medellin, on the side of the } \\
\text { La Alpujarra Square }\end{array}$ & part of a spa / health resort park & $\begin{array}{l}\text { part of a sports area in the town } \\
\text { of Morgex, connected with } \\
\text { educational pathway }\end{array}$ \\
\hline Number of different materials & 5 & 26 & 21 \\
\hline Rigid versus loose material & $3 / 2$ & $14 / 12$ & $11 / 10$ \\
\hline $\begin{array}{l}\text { Transition between different } \\
\text { surfaces }\end{array}$ & $\begin{array}{l}\text { transition to other materials, } \\
\text { depending on the direction of } \\
\text { movement }\end{array}$ & $\begin{array}{l}\text { almost every transition between } \\
\text { the stands includes grass }\end{array}$ & $\begin{array}{l}\text { different transitions depending on } \\
\text { the next material }\end{array}$ \\
\hline Number of transitions & 7 & 40 & 31 \\
\hline $\begin{array}{l}\text { Structure of the area with } \\
\text { stands }\end{array}$ & $\begin{array}{l}\text { one solid area } \\
\text { approximately } 45 \mathrm{~m}^{2}\end{array}$ & $\begin{array}{l}\text { trail with different stands } \\
\text { connected by grass paths, length } \\
\text { of trail approximately } 2000 \\
\text { metres }\end{array}$ & $\begin{array}{l}\text { trail from different surfaces } \\
\text { usually transitioning to the } \\
\text { next material, length of trail } \\
\text { approximately } 800 \mathrm{~m}\end{array}$ \\
\hline Area boundary & open area, no fence & $\begin{array}{l}\text { fenced area, possible visits } \\
\text { during opening hours of spa } \\
\text { resort's park }\end{array}$ & open area, no fence \\
\hline Usual visitors & locals & visitors to spa & locals and tourists \\
\hline $\begin{array}{l}\text { The colour of the material } \\
\text { (impact on the temperature) }\end{array}$ & $\begin{array}{l}\text { natural variability of colours of } \\
\text { materials used }\end{array}$ & $\begin{array}{l}\text { natural variability of colours } \\
\text { of materials used, one stand } \\
\text { especially dedicated to different } \\
\text { temperatures and different colours }\end{array}$ & $\begin{array}{l}\text { natural variability of colours of } \\
\text { materials used }\end{array}$ \\
\hline Information system & $\begin{array}{l}\text { The information system only } \\
\text { invites people to take off their } \\
\text { shoes }\end{array}$ & $\begin{array}{l}\text { A large map with an overview } \\
\text { at the beginning and then an } \\
\text { information table for every stand }\end{array}$ & $\begin{array}{l}\text { A large map with an overview at the } \\
\text { beginning and then tables that are } \\
\text { mainly for educational pathwalk }\end{array}$ \\
\hline
\end{tabular}


Tab. 2 Table of surfaces in Landererov Park (M. Majorošová, 2020).

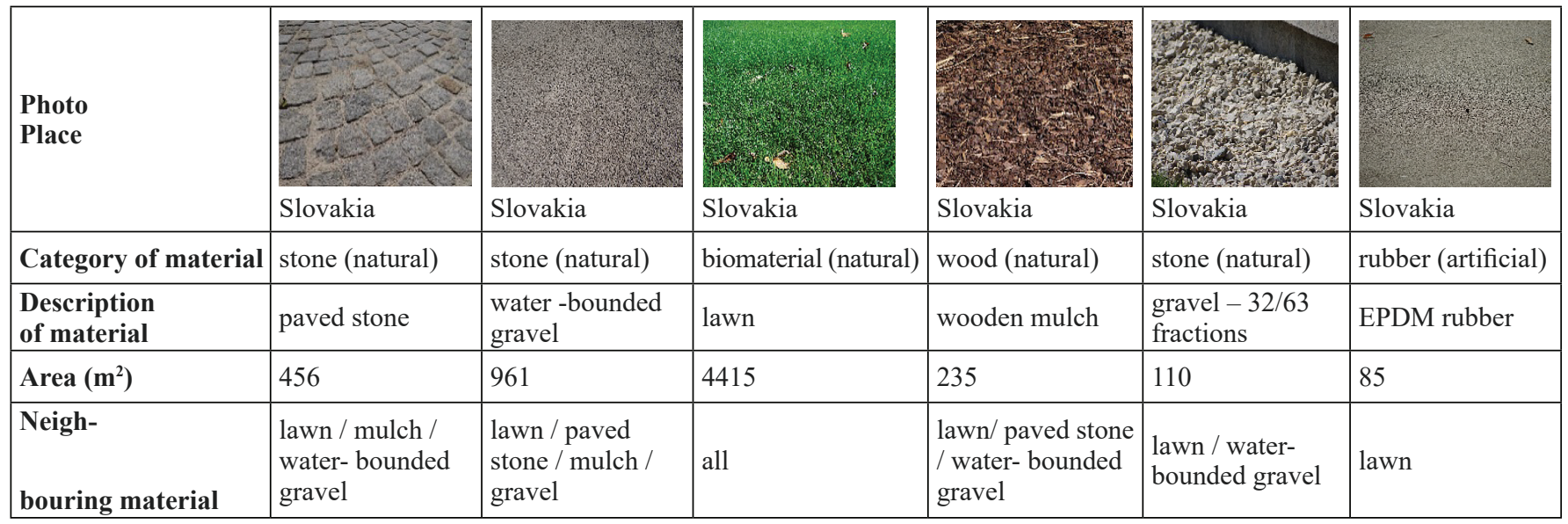

\subsection{Potential of Landererov Park in Slovakia - an example of the recognition and design of a stimulative space}

Landererov Park measures around $8000 \mathrm{~m}^{2}$ and includes six surfaces with different levels of hardness (see Table 2). These materials are situated in various places in the park, see Figure 2. The design of the park offers six transitions from one material to another. Even though the walking paths cross the park, free movement in all the areas is also possible. The central part of the park consists of a fountain that has an aesthetic function only, and it is not accessible to visitors as a refreshing element. The park itself is situated in an older part of Bratislava; therefore, its visitors are not only locals but also tourists. The area is not fenced, and it is open during the night too. The main idea during the reconstruction of the park was to bring in more greenery and a calm place offering relaxation and new functions in the urban city area.

Based on the previous parameter analyses, the site itself has a high potential to be a stimulative area or offer stimulative stands. Because of the size of the park, an information system to motivate visitors to unshod themselves and to present the activity of barefoot walking is needed. Tables with instructions situated in different places in the park would inform people that are coming from different directions to try barefooting. The costs of this project would include the costs of an information system and fencing construction or a responsible employee.

An important question to answer was whether it would be better to create barefoot stands or a barefoot area. A specific barefoot trail
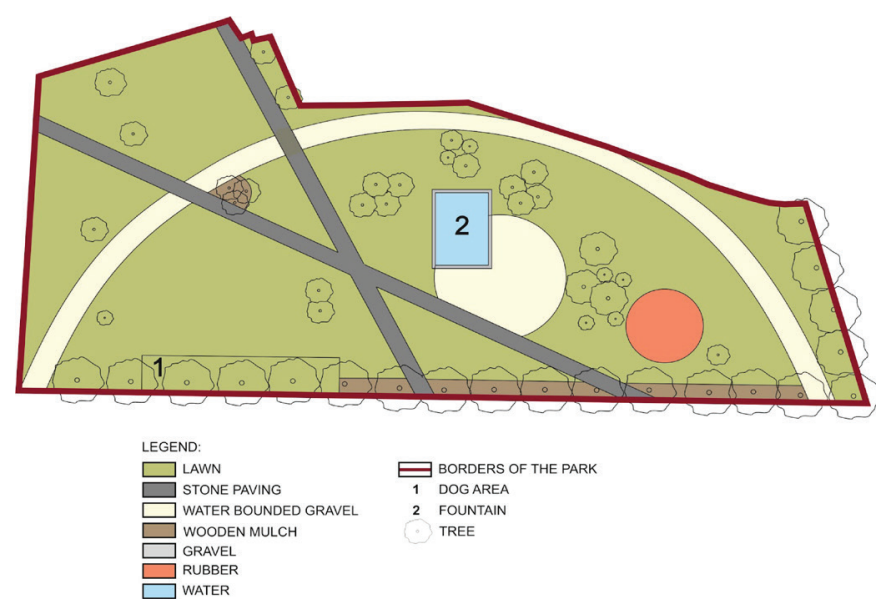

Fig. 2 Different surfaces in Landererov Park (M. Majorošová, 2020). in Landererov Park would be easier to maintain than a whole barefoot park, and it would be easier to situate information tables. On the other hand, some of the surfaces are not meant to be visited with a high degree of frequency. When people go through the same route every day, the lawn starts to lose its homogeneity, and the route is visible.

Based on this fact a barefoot area for the free movement of visitors is a better option for the sustainability of the park. This option includes a larger area to maintain and proper placement of an information system.

The different approaches for an information system can be used for barefoot parks or trails. The first approach consists of a set of informative tables, where every table motivates visitors to unshod themselves, gives the fundamental information about barefoot walking, and recommends the place in the park with the main table with all the information. The placement and number of tables can vary, but they should be evenly distributed next to every entrance (see Figure 3). The whole barefoot story should be complete after reading one table in the centre of the park.

The second approach consists of a main table with general information about barefooting; it should motivate visitors to take off their shoes. The other tables can be placed along the suggested barefoot trail, and each spot will give new information about the different surface (see Figure 4). The whole barefoot story will be complete after finishing the whole barefoot trail and reading all the tables.

We can recommend either approach for Landererov Park; however, the second approach considers free movement on the lawn area.

\section{CONCLUSIONS}

Analyses of some existing stimulative spaces point to three possible approaches to the creation of a stimulative space, i.e., a stimulative stand, stimulative pathway, and stimulative area. By following the parameters in the table, it is possible to easily and quickly determine the potential of any space for the barefooting function.

The example of Landererov Park in Bratislava, which was not reconstructed for the purpose of being a barefoot area, shows that even a spacious park can offer a stimulative space without any major design interventions. Interventions can be inexpensive, fast, efficient, if the appropriate way to design and maintain a barefoot space is chosen.

The number of materials and transitions between different surfaces offer various stimulation possibilities for feet. For this purpose, two main investments are needed. The first one is a set of informative tables about barefoot benefits, conscious walking, practical tips, safety information, and motivations to take off shoes. The second neces- 


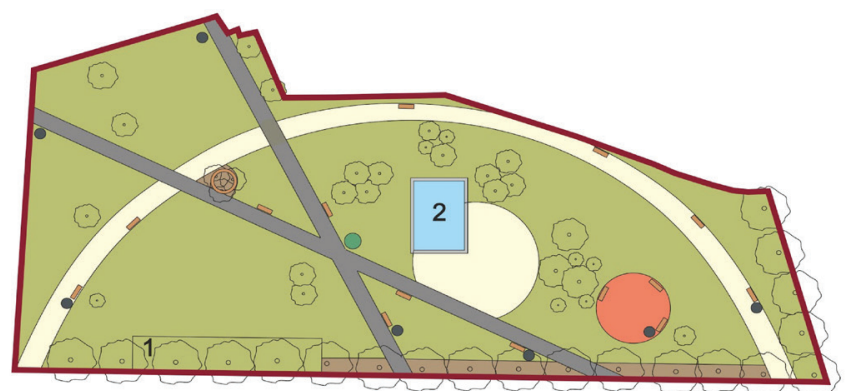

LEGEND APPROACH 1:

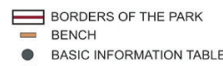
BASIC INFORMATION TABL TREE

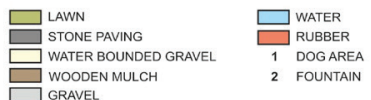

Fig. 3 Approach No.1 for Landererov Park (M. Majorošová, 2020).

sary investment is to provide for the cleanliness and safety of the area by a responsible employee or to fence the area. The design presented and the placement of the information system can be inspirational for the creation of new stimulative spaces. New functions of the parks selected can enrich the possibility of different areas for relaxation in the city for locals and can also be a very interesting touristic stopover for visitors.

One of the most important things is to bring about the possibility of walking barefoot in cities and give people areas where they can move and train their feet. The use of feet as they were created by evolution and a change in the way of walking could lead to a minimization of plantar problems and related movement difficulties.

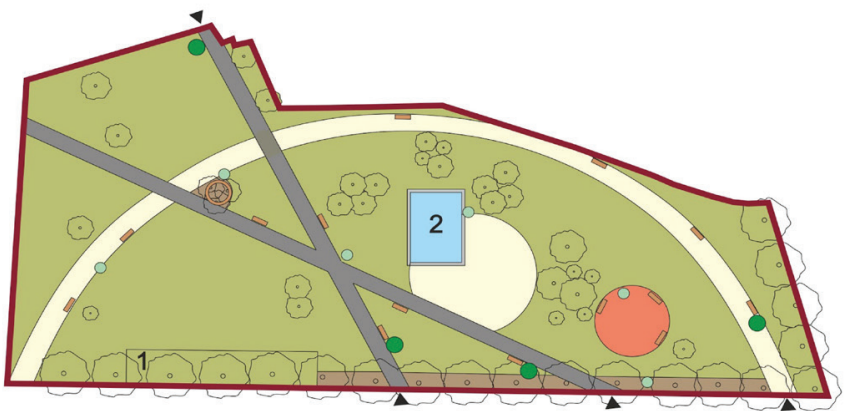

LEGEND APPROACH 2 :

$\Longrightarrow$ BORDERS OF THE PARK - BENCH

BASIC INFORMATION TABLE

THE MOST FREOUENTED ENTRM

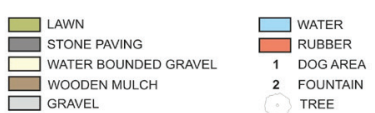

Fig. 4 Approach No. 2 for Landererov Park (M. Majorošová, 2020).

\section{Acknowledgments}

This study has been supported by the Scientific Grant Agency (Slovakia) under VEGA Contract No. 1/0068/19. 


\section{REFERENCES}

Belčáková, I. - Galbavá, P. - Majorošová, M. (2018). Healing and therapeutic landscape design - examples and experience of medical facilities. International Journal of Architectural Research: ArchNet-IJAR, [S.1.], 12, (3), pp. 128-151.

D'aout K. - Pataky T. C. - DE Clercq D. - Aerts P. (2009). The effects of habitual footwear use: foot shape and function in native barefoot walkers. Footwear Sci 2009;1(2):81-94.

Engle E.T. - Morton D. J. (1931). Notes on foot disorders among natives of the Belgian Congo. Journal of Bone and Joint Surgery, $13,311-318$.

Franklin, S. - Grey, M. J. - Heneghan, N. - Bowen, L. - Li, F. X. (2015). Barefoot vs common footwear: A systematic review of the kinematic, kinetic and muscle activity differences during walking. Gait \& Posture, doi:10.1016/j.gaitpost.2015.05.019.

James C.S. (1939). Footprints and feet of natives of the Solomon Islands. Lancet, ii, 1390-1393.

Kapski, D. - Kot, Y. -Lutsenko, T. - Prasolenko, O. - Galkin, A. - Lobashov, O. - Dulfan, S. (2020). Assessing the Effect of Turning Vehicles and Pedestrians on the Safety of an Urban Road Section (Using Examples from the Commonwealth of Independent States), Slovak Journal of Civil Engineering, 28(2), 8-17. doi: https://doi.org/10.2478/sjce-2020-0009

Lieberman, D. (2013). The story of the human body: 12 The Hidden Dangers of Novelty and Comfort. Why Everyday Innovations Can Damage Us (pp. 342-346). Allen Lane.

Lythgo N. - Wilson C. - Galea M. (2009). Basic gait and symmetry measures for primary school-aged children and young adults whilst walking barefoot and with shoes. Gait Posture 2009;30(4):502-6.

Mazancova, E. - Kotradyova, V. (2017). Stimulative floor surfaces in interior-barefoot philosophy in home interior. Healthy Houses - Healthy Interior 2017 Conference, Slovak Republic, 23-25 Sept. 2017.

Menant J.C. - Steele J. R. - Menz H. B. - Munro B. J. - Lod S. (2008). Optimizing footwear for older people at risk of falls. J Rehabil Res Dev 2008;45(8):1167-81.
Oeffinger D. - Brauch B. - Cranfill S. - Hisle C. - Wynn C. - Hicks R. , et al. (1999). Comparison of gait with and without shoes in children. Gait Posture 1999;9(2):95-100.

Robbins S.E. - Hanna A. M - Gouw G. J. (1988). Overload protection avoidance response to heavy plantar surface loading. Medicine \& Science in Sports \& Exercise, 20, 85-92.

Robbins S. E. - Hanna A. M. - Gouw G. J. (1987). Running-related injury prevention through barefoot adaptations. Medicine \& Science in Sports \& Exercise, 19, 148-156.

Rossi W. A. (1999). Why Shoes Make "Normal" Gait Impossible. How Flaws in Footwear Affect This Complex Human Function, in "Podiatry Management". (pp. 52-61)., https:// static1.squarespace.com/static/5832fb2ce 4 fcb 5 e $251 \mathrm{~d} 9 \mathrm{bc}-$ c5/t/742f774578e/1504611224068/rossiWhyShoesMakeNormalGaitImpossible.pdf.

Schulman S. B. (1949). Survey in China and India of feet that have never worn shoes. Journal of the National Association of Chiropodists, 49, 26-30.

Souter-Brown G. Landscape and Urban Design for Health and Well-Being. London: Routledge. Retrieved Mar. 11, 2018, from https://doi.org/10.4324/9781315762944

Squadrone R. - Gallozzi C. (2009). Biomechanical and psysiological comparison of barefoot and two shod conditions in experienced barefoot runners. J Sports Med Phys Fit 2009;49(1):6.

Tolja, J. - Don, N. (2019). Corpo moda mente: Edizioni il punto d'incontro (24 pp. [in print]).

Trinkaus, E. - Shang, H. (2008). Anatomical evidence for the antiquity of human footwear: Tianyuan and Sunghir. J Archaeol Sci 2008; 35 (7):1928-33. doi:10.1016/j.jas.2007.12.002.

Wolf S. - Simon J. - Patikas D. - Schuster W. - Armbrust P. - Doederlein L. (2008). Foot motion in children shoes - a comparison of barefoot walking with shod walking in conventional and flexible shoes. Gait Posture 2008;27(1):51-9. 